\title{
CICLO BIOLÓGICO DE Oryctes sp (COLEOPTERA: SCARABAEIDAE)
}

\author{
Lorenzo R. Beck ${ }^{2}$ \\ Menandro S. Ortiz ${ }^{2}$
}

\section{RESUMEN}

Se estudia el ciclo biológico de Oryctes sp, coleóptero de la Familia Scarabaeidae (Dynastinae) en el Departamento de San Martín, Perú en condiciones de laboratorio. Se determinó el período de incubación, la duración de los tres períodos larvales, el pupal y la longevidad de los adultos, machos y hembras,

Palabras claves: Oryctes sp, ciclo biológico, Scarabaeidae, Dynastinae.

\section{SUMMARY}

The biological cycle of Oryctes sp, beetle of the Scarabaeidae family (Dynastinae) is studied at the department of San Martin (Peru) at laboratory conditions. The incubation period, the time of the three larval periods and the longevity of the adults, male and female were determined.

Key words: Oryctes sp, biological cycle, Scarabaeidae, Dynastinae.

\section{INTRODUCCIÓN}

Se señala en todo momento que nuestro país es uno de los más importantes en lo referente a la diversidad biológica. Pero en realidad ¿qué tanto conocemos?; sí se tiene en cuenta que no menos del $45 \%$ del territorio nacional existen vacíos de información sobre este aspecto. Si bien es cierto que en éstos último tiempos, se vienen realizando trabajos en mamíferos, aves y peces, por diversas instituciones, se aprecia que los estudios sobre artrópodos y sobre todo en insectos son muy escasos en el Perú.

Entre los insectos, los coleópteros incluyen más de 300,000 especies descritas, por lo que conforman el orden más amplio del reino animal. Su adaptabilidad y las modificaciones estructurales que presentan han contribuido a que tengan hábitats terrestres y acuáticos.

Cumplen un rol muy importante. Se presentan en asociaciones estrechas con plantas herbáceas, arbustos y árboles, alimentándose de diversos órganos de estos hospederos. También existen los saprófagos, como aquellos que se alimentan de la madera descompuesta, de animales muertos. Otros son coprófagos, como los son los escarabajos peloteros, quienes trasladan esta materia hacia sus nidos como alimento para sus larvas.
Sin duda esta acción permite la eliminación de estos sustratos y la fertilización del suelo.

Otras especies de coleópteros, al tener como hábitat el suelo, es decir tienen una vida hipogea, como lo son las larvas de los Scarabaeidae, además de alimentarse de las raíces, hacen posible que se lleve a cabo la oxigenación del suelo al remover la tierra y permitir el movimiento capilar del agua en el suelo.

El ser humano, considera benéficos a aquellos coleópteros que se alimentan de plantas indeseables o malezas; mientras que considera plaga a aquellos que dañan cultivos y bosques o cuando afectan de manera adversa los valores ecológicos, sociales o económicos. Sin duda muchos habitantes los consideran como parte de la dieta que consumen.

Es aquí donde encontramos la importancia y necesidad de estudiar a este grupo de insectos, ya que se ha señalado que diversas especies presentan un variado comportamiento, resaltando el valor alimenticio que tiene Oryctes sp. Sin duda trabajos de ésta naturaleza, servirán de base para posteriores estudios sobre este campo.

En nuestro país, los estudios en desarrollo postembrionario y ciclos biológicos en coleópteros son

Facultad de Ciencias Biológicas, Universidad Ricardo Palma, Av. Benavides 5440, Lima-Perú.

Facultad de Medicina Humana y Facultad de Ciencias Biológicas, Universidad Ricardo Palma, Av. Benavides 5440, Lima-Perú,

e-mail: mesorpre@hotmail.com 
muy escasos, principalmente en la subfamilia Dynastinae, convirtiéndose por esta razón en el objetivo principal de éste trabajo.

\section{ANTECEDENTES}

No existiendo literatura disponible en nuestro medio, se precisa presentar algunos estudios realizados fuera del país, así Schread (1974) señaló que Papilia japoni$c a$ se introduce al suelo en horas vespertinas y deposita alrededor de 40 a 60 de huevos. Por la longevidad de su ciclo biológico, produce una sola generación al año.

Hadley y Hawley (1934) mencionan que el escarabajo japonés en su tercer estadío larval pasa el invierno dentro de una celda a $13 \mathrm{~cm}$ de la superficie del suelo. Luego de 10 días se transforman en pupa, emergiendo los adultos después de 8 a 10 días, dependiendo ello fundamentalmente de la temperatura. Indican que en los días templados los escarabajos vuelan y se alimentan vorazmente de las hojas de las rosas, melocotones y otras plantas, con tendencia gregaria.

Fleming (1970) señala que los adultos emergen por lo general en los últimos días de mayo en Carolina del Norte, USA. Poco tiempo después de la emergencia empiezan a aparearse.

Couterier y Robert (1955), en relación a Melolontha melolontha, indican que permanecen en diapausa durante todo el otoño e invierno. La emergencia se inicia a partir de la segunda quincena de abril. Por otros lado, Guerrero (1964) reporta que al final de la diapausa no se realiza de un modo uniforme para todas las hembras, es decir aquellas que salen del suelo no presentan un desarrollo homogéneo de sus ovarios.

Hurpin (1961) refiere que los adultos de Rhizotrogus oestivus aparecen también a partir de la segunda quincena de abril; las hembras vuelan durante el crepúsculo y llegan a plantas bajas cercanas, en donde son apareadas. Al parecer, existe una sola generación al año. Las larvas se alimentan de raíces.

Respecto a Amphimallon solsticialis, Hurpin y Mailard (1952) señalan que el ciclo evolutivo es de dos años y que la hibernación es de dos años. Agregan que las hembran son menos activas que los machos. En contraste $A$. majalis presenta un ciclo de un año.

En nuestro país, Ochoa (1974) registró a Heterogomphus ochoai (Dynastinae), cuyos huevos son hipodáfi$\mathrm{cos}$, con una profundidad de $10 \mathrm{a} 20 \mathrm{~cm}$ de profundidad. Son ligeramente ovalados, de 3 a $4 \mathrm{~mm}$ de longitud y 3 a 3,5 $\mathrm{mm}$ de diámetro; de color blanquecino. Incuva alrededor de 40 días. Posee tres estadíos larvales. La larva recién emergida mide 4 a $6 \mathrm{~mm}$ con una longevi- dad de alrededor de 6 meses. El segundo estadío larval llega a tener entre 20 a $40 \mathrm{~mm}$, son muy voraces y presentan una longevidad de 8 a 9 meses. Finalmente el tercer y último estadío larval alcanza entre 50 a $70 \mathrm{~mm}$ de longitud con 6 a 7 meses de longevidad. La pupa se halla dentro de una cámara pupal.

En lo concerniente a especies que pertenecen al género Oryctes, contamos con $O$. nasicornis, en donde es posible observar en el aspecto ventral del segmento subterminal, por su transparencia, el órgano de Herolt (con un punto terminal esclerotizado), lo que es característica de los machos. El órgano de Herolt tiene el aspecto de un pequeño triángulo. Esta estructura ayuda a determinar los sexos en larvas de último estadío $\left(\mathrm{L}_{3}\right)$, con algunas excepciones.

\section{MATERIALES Y MÉTODOS}

El ciclo biológico de Oryctes sp fue ejecutada a 300 msnm en el Laboratorio del Centro de Interpretación del Parque Nacional del Rio Abiseo, en el distrito de Huicungo, Departamento de San Martín, bajo condiciones ambientales de temperatura entre $26,9 \pm 2^{\circ} \mathrm{C}$ y con una humedad relativa de $86,4 \pm 2 \%$ durante doce meses posteriores a la obtención del material inicial del estudio; de setiembre de 2000 hasta agosto de 2001, período en que se obtuvo una sola generación.

\section{Colecta de especímenes}

Se colectaron 10 parejas, sexualmente maduras, del interior de distintos tallos de Ginerium sagitattum (caña brava), ubicados en ambos márgenes del río Huallabamba, en la localidad de Huicungo.

Los ejemplares elegidos se trasladaron al laboratorio en donde se les dispuso por parejas, en diez jaulas de vidrio de $30 \times 30 \times 6 \mathrm{~cm}$ tapados con malla metálica, permitiendo de ésta manera la ventilación y evitando además la fuga de los ejemplares.

Las jaulas contuvieron $10 \mathrm{~cm}$ de altura de tierra húmeda; y a cada una se le colocó un tallo de G. sagitattum de $15 \mathrm{~cm}$ de longitud, a las cuales se les practicó una hendidura de $7 \mathrm{~cm}$ de longitud, las que les sirvió como un lugar de protección. Este tallo les sirvió también como alimento; y fue cambiado de 2 a 3 días. De éstas parejas se obtuvieron los huevos requeridos .

Cuando se empezó a la observación del ciclo biológico, se separaban 1 ó 2 muestras de cada uno de los estadíos con la finalidad de apreciar los aspectos morfológicos, con la ayuda de una estereopio Carl Zeiss a 40x. Las larvas, para el estudio correspondiente, fueron muertas en primer lugar con agua caliente y posteriormente fueron preservadas en alcohol de $70 \%$. La nomenclatura usada para los diferentes aspectos morfológicos, se 
realizaron siguiendolos lineamientos de Peterson (1953).

Para observar el proceso de maduración de los huevos, se tomaron 20 de ellos, recién ovipositados, disponiéndolos en placas Petri, hasta la eclosión. Fueron revisados diariamente para evitar la contaminación de hongos o de otros organismos perjudiciales.

En ello se observó el tiempo de incubación en días y fueron hechas las mediciones correspondientes.

Producida la eclosión de los huevos, las 20 larvas emergentes se individualizaron en envases de un litro de capacidad, conteniendo como sustrato alimenticio el tronco en descomposición de la palmera Maurita flexusosa (aguaje). Este fue desmenuzado y secado al sol durante 4 a 7 días, posteriormente fue esterilizado a una temperatura de $40^{\circ} \mathrm{C}$ durante 30 minutos. Finalmente fue humedecido e introducido a los envases en donde se encontraban las larvas. Los envases se manutuvieron constantemente cubiertos con tul, favoreciendo de esta manera una buena circulación de aire.

Posteriormente se llevó a cabo el monitoreo larval. Diariamente se observaron a las larvas para mantener la humedad adecuada del sustrato alimenticio, así como determinar en forma precisa el tiempo exacto de duración de los diferentes estadíos larvales.

Una vez que las larvas completaban su máximo desarrollo y formando parte del último estadío larval, aparece la fase de la prepupa. Estas últimas se dispusieron en envases de 0,5 1 de capacidad, conteniendo tierra húmeda esterilizada, a la que se le practicó una concavidad, con la finalidad de representar una pequeña cámara pupal, cubriéndolos con un círculo de cartulina negra. Posteriormente la siguiente etapa de desarrollo correspondió a la pupa.

Las pupas fueron mantenidas de la misma manera que las prepupas, pero al esperar seguidamente a los adultos, se optó por tapar el envase con tul, sujeto con una banda elástica. Las pupas fueron tomadas cuidadosamente para determinar el sexo de cada una de ellas. El método fue directo, observando el dimorfismo sexual entre las pupas correspondientes a machos y a hembras. Las pupas de machos presentan una protuberancia en la parte dorsal de la cabeza, el cuerno característico de las especies de la Subfamilia Dynastinae; en cambio las pupas hembras no presentan ningun tipo de protuberancia, al no presentar cuerno en la etapa adulta.

Cada envase fue etiquetado, anotándose el sexo y la fecha de empupamiento de cada uno de los ejemplares.

\section{RESULTADOS}

Los ejemplares adultos se remitieron al Museo de Entomología de la Universidad Nacional Agraria, La Molina, para su identificación. Resultó ser Oryctes sp perteneciente a la subfamilia Dynastinae de la familia Scarabaeidae.

El huevo es de forma oval, color blanco hialino en posturas recientes, convirtiéndose en globular y de color blanco cremoso conforme se acerca el momento de la eclosión. Para esta única generación, el período de incubación promedio fue de 15,05 días, después de la oviposición, con un máximo de 16 días y un mínimo de 14 a una temperatura promedio de $27,5^{\circ} \mathrm{C}$ y una humedad relativa de $86,7 \%$. Los huevos recién ovipositados presentan una longitud y un ancho promedio de 3,69 mm y 2,65 mm, respectivamente. Un día antes de la eclosión ya se puede visualizar una pequeña larva bien formada de color blanquecino, a través de la pared del huevo.

En lo que respecta al desarrollo post-embrionario se indica que la larva es de forma cilíndrica, algo arqueada, con una cabeza bien desarrollada y piezas bucales adaptadas para la masticación. Son hemipneústicas, es decir presentan 9 pares de espiráculos, estando ubicado el primer par entre el protórax y mesotórax y los otros en los 8 primeros segmentos abdominales. Se halló tres estadíos larvales.

La larva recién eclosionada mide aproximadamente 10,24 mm de longitud y la cápsula cefálica se presenta de color marrón oscuro y mide $3,25 \mathrm{~mm}$ de diámetro. Este primer estadío larval tuvo una duración promedio de 19,11 días. El día previo, antes de pasar al segundo estadío larval alcanzó una longitud promedio de 19,89 mm. El cuerpo es de color blanco transparente; sin embargo conforme empieza a alimentarse se va oscureciendo hasta tomar un color gris claro. La fase final de la muda (ecdysis) ocurre durante el ocaso y al amanecer ya se encuentra en el segundo estadío larval.

La larva de segundo estadío mantiene la misma coloración y aspectos morfológicos, diferenciándose por el volumen corporal, el cual casi duplica al primer estadío. Alcanza una longevidad máxima de 33 días, con un promedio de 26,64 días; con una longitud promedio de $40,33 \mathrm{~mm}$

En el tercer estadío, igualmente, la coloración no varía, la larva alcanza su máximo desarrollo y se puede diferenciar aquellas que van a dar lugar a machos y a hembras. Ello se observa gracias a que en el último estadío aparece en medio de la parte ventral del segmento subterminal el órgano de Harolt (con el punto terminal esclerotizado), característica de los machos. 
Alcanza una duración promedio de 137,87 días y la longitud del cuerpo varía entre $60,90 \mathrm{~mm}$ y $70,62 \mathrm{~mm}$. En éste estadío, sin muda previa, ocurre la formación de la prepupa. Es decir, la primera fase de éste estadío larval se considera como nutricional hasta iniciar la formación de la prepupa.

La prepupa se caracteriza por un encogimiento del último estadío larval; se acentúan los anillos intersegmentales, presentando además un cambio de coloración de la larva que pasa a un color entre amarillo opaco y marrón oscuro. Pierde por completo la movilidad. Como ya se ha indicado, esta fase se desarrolla sin muda previa. El promedio de longevidad de la prepupa alcanzó 62,93 días. Se deja constancia que en ésta época se contó con una mayor temperatura y un fotoperíodo mayor.

La pupa es de tipo exarate; recién formada es de color blanco cremoso y conforme pasan las horas se torna de color marrón. En la cabeza se pueden diferenciar los ojos y cada parte de las piezas bucales. Además se pueden diferenciar los sexos, dado que los machos presentan un a protuberancia en la parte dorsal de la cabeza, el que dará lugar al cuerno cefálico característico, cuando adultos. El abdomen presenta 9 segmentos y un par de apéndices en el último segmento observado.

Los adultos se caracterizan por presentar una cabeza de color marrón. El macho presenta un acuerno cefálico de aproximadamente $5 \mathrm{~mm}$ de largo. El tórax, los élitros y el abdomen son de color marrón oscuro. En cuanto al comportamiento, tanto en el laboratorio como en el campo, estos se alimentan de tallos y raíces. Su mayor actividad, tanto en alimentación, apareamiento y oviposición es nocturna. Durante el día prefieren ocultarse en el subsuelo, lo cual dificulta su localización en el campo, salvo en la época de apareamiento, los que se visualizan sobre el tallo de G. sagittatum.

Como se aprecia, el desarrollo post-embrionario de Oryctes sp, comprende el período de desarrollo de la larva y el período de desarrollo de la pupa, la que se logró en condiciones de laboratorio utilizando como alimento troncos en descomposición de la palmera $M$. flexuosa, comúnmente denominada aguaje. Oryctes sp presentó entonces una período de incubación y desarro1lo post-embrionario máximo de 363 días y un mínimo de 290 días. Particularmente las hembras alcanzaron un promedio de 325,55 días, en cambio los machos alcanzaron un promedio ligeramente menor de 315 días, lo que está dentro del rango de alguna especies de Dynastinae.

\section{DISCUSIÓN}

Realmente existe poca información sobre el desarrollo biológico de especies que pertenecen a la subfamilia Dynastinae, a la que pertenece Oryctes sp. Consecuentemente, con la finalidad de establecer comparaciones, se presentarán algunos datos de otras especies de Scarabaeidae que estén relacionadas.

La especie Heterogomphus ochoai, perteneciente a la subfamilia Dynastinae presenta huevos hipodáficos, ligeramente ovalados, de 3 a 4 mm de longitud, de color blaquecino, según lo establecido por Ochoa (1974). Estos datos son semejantes a los hallados en Oryctes sp, ya que presenta también huevos hipodáficos, ligeramente ovalados con un rango de 3,30 a $3,95 \mathrm{~mm}$ de longitud. En donde se encuentra diferencia es en el período de incubación, ya que la primera especie tiene un tiempo promedio de 40 días y la especie en estudio presentó un promedio de 15,05 días. Por otro lado esta especie presenta también tres estadíos larvales, de manera similar a lo hallado en el presente estudio. Por otro lado la larva de primer estadío mide de 4 a $6 \mathrm{~mm}$ con una longevidad de dos meses. Estos datos difieren con lo hallado respecto a Oryctes sp, ya que los datos respectivamente son 2,30 a $3,25 \mathrm{~mm}$ y 19,11 días. Respecto al segundo estadío larval también existen variaciones. Se estima que ello se debe a que son dos especies diferentes y que las condiciones de crianza variaron en algo, a pesar que ambas especies pertenecen a la subfamilia Dynastinae; sin embargo respecto al tercer estadío si hay similitud, en lo concerniente a la longitud, la que alcanza entre 50 a $70 \mathrm{~mm}$ con una longevidad de seis a siete meses para la especie que estudió este autor, quien agrega que esta especie presenta una pupa con un longitud de $40 \mathrm{~mm}$ y una duración de 2 a 3 meses. En parte es coincidente con lo hallado para Oryctes sp, no así respecto al tiempo de duración, siendo éste mucho menor, de 28 a 32 días.

De acuerdo a Robert (1994), una especie relacionada Oryctes nasicornis presenta el órgano de Harolt en el segmento abdominal subterminal, de la misma manera que Oryctes sp.

Por otro lado, a manera de comparación, la eclosión de los huevos de Melolontha melolontha, miembro de la subfamilia Melolonthinae, se realiza de cuatro a cinco semanas después de la puesta; y que éstos no se desarrollan a una temperatura constante e inferior a $\operatorname{los} 11^{\circ}$ $\mathrm{C}$ o superior a $\operatorname{los} 25^{\circ} \mathrm{C}$ y cuando el porcentaje de humedad del terreno es inferior al $5 \%$ o superior al 16 $\%$, según lo reportado por Hurpin y Mailland (1952). La incubación de Phyllopertha horticolas (Rutelinae) presenta una duración de 4 a 6 semanas a $15-17^{\circ} \mathrm{C}$ según Milne y Laughlin (1956); lo cual contrasta con los 15 días en promedio, antes citado para el caso de Oryctes sp, a una temperatura promedio de $27,5^{\circ} \mathrm{C}$ y una humedad relativa de $86,7 \%$. 


\section{CONCLUSIONES}

De los resultados obtenidos acerca del desarrollo de Oryctes sp, alimentados con la palmera $M$. flexuosa durante doce meses, se tiene las siguientes conclusiones:

1. El período de incubación tiene una duración promedio de 15,05 días.

2. Oryctes sp presenta tres estadíos larvales, cuyos promedios de vida son los siguientes: el primer estadío: 19,11 días, el segundo estadío: 26,64 días y el tercer estadío 62,93 días.

3. El diámetro transversal promedio de la cápsula cefálica del primer estadío larval es $3,25 \mathrm{~mm}$, el del segundo es de 6,07 $\mathrm{mm}$ y el del tercero es de 10,42 $\mathrm{mm}$.

4. El período pupal es de 29,75 días.

5. El desarrollo post-embrionario tiene una duración promedio de 305,87 días.

6. La etapa de incubación, sumada al desarrollo postembrionario presentan una duración de 320,81 días, con un rango que oscila entre 290 y 363 días.

7. Las hembras son más longevas que los machos, alcanzando un promedio de vida de 295,66 días las hembras y los machos 285,42 días.

\section{LITERATURA CITADA}

COUTURIER, A. y G. Robert. 1955. Recherche sur le compotement du hanneton commun (Melolontha melolontha L) au cours de sa vie aérienne. Ann. I.N.R.A., s'rie Epiphyties 5: 19-60.

FLEMING, W. 1970. The Japanese beetle in the United States. U.S. Dept. Agr., Agr Res.Ser. Agr. Handb., 236, 30 pp.

GUERRERO, F. 1964. Enemigos naturales de plantas cultivadas y forestales. Ediciones de Occidente, Barcelona, 241-257.

HADLEY, C. y I. Hawley. 1934. General information about the japanese beetle in the United States. U.S. Dept. Agr., Circ.332.23 p.

HURPIN, B. 1961. Sachons distinguer entre les nombreuses espéces de Vers blancs. Phytoma, 129: 1116.

HURPIN, B. y J. Maillard. 1952. Remarques sur biologie d'Amphimallon solsticialis L (Coleoptera: Scarabaeidae). Bull. Soc. Ent. Fr., 57: 58-61.

MILNE, A. y R. Laughlin. 1956. Biology and ecology of the garden chafer Phyllopertha horticula. The adult and egg production. Bull. Ent. Research, 47: 7-22.

OCHOA, M. 1974. Ciclo biológico, morfología y comportamiento de Heterogomphus ochoai Martinez, 1966 (Coleoptera: Scarabaeidae, Dynastinae). Rev. per. Ent., 17:3-9.

PETERSON A. 1953. Larvae of Insects. Part II. Columbus, Ohio State University, pp. 1-128.

ROBERT, P. 1994. Oryctes nasicornis. El diario de los insectos. Publicado por OPIE.

SCHREAD, J. 1974. Japanese Beetle-life history and control. Com. Agr. Exp. Sta. Bull., 20 pp. 